\title{
Effect of spatial arrangement of presynaptic calcium channels on the calcium current cooperativity of neurotransmitter release
}

\author{
Victor Matveev ${ }^{1 *}$, Richard Betram²,3, Arthur Sherman ${ }^{3}$ \\ From Twentieth Annual Computational Neuroscience Meeting: CNS*2011 \\ Stockholm, Sweden. 23-28 July 2011
}

Interaction between calcium nanodomains of individual voltage-dependent calcium channels in triggering exocytosis in neurons and endocrine cells is of significant importance for understanding localized calcium signaling in general and synaptic physiology in particular. Such channel domain interaction (overlap) is often experimentally probed by measuring the sensitivity of release rate to the total presynaptic calcium current, which is varied by changing the number of open channels while the single-channel current is kept fixed. Variation in the number of activated channels is in turn achieved using appropriate voltage-clamp protocols, or by pharmacologically blocking a subset of channels. The resulting slope of the log-log regression line between release rate and total calcium current is termed calcium current cooperativity, and is believed to indirectly probe the number of channels contributing to the exocytosis of a single vesicle (reviewed in [1]). If for instance each vesicle is coupled to a single channel, then neurotransmitter release rate would be linearly proportional to the number of open channels, leading to a current cooperativity value of $\sim 1$, whereas this relationship would be non-linear if many channels contribute to a single exocytosis event, resulting in higher current cooperativity.

Due to the indirect nature of such current cooperativity assay, mathematical and computational modeling proved valuable in the analysis of this experimental protocol [2-7]. Here we use modeling of spatio-temporal calcium diffusion and buffering to explore more precisely the relationship between calcium current cooperativity and the underlying number of calcium channels contributing

\footnotetext{
* Correspondence: matveev@njit.edu

'Department of Mathematical Sciences, New Jersey Institute of Technology, Newark, NJ, USA

Full list of author information is available at the end of the article
}

to vesicle release. We focus on the dependence of current cooperativity on the morphology of the active zone, in particular its dependence on the number of channels contributing to neurotransmitter release, both in the equidistant channel configuration, and for distinct nonequidistant channel distributions. Our general finding is that, under all conditions studied, current cooperativity significantly underestimates the number of channels contributing to the release of a single neurotransmitter vesicle, even when only a few channels contribute to release under condition of low release saturation. We also examine the implications of distinct current cooperativity values for the variability of synaptic transmission.

\section{Acknowledgements}

Supported by the National Science Foundation grants DMS-0817703 (V.M.) and DMS-0917664 (R.B.), and the NIDDK/NIH Intramural Research Program (A.S.).

\section{Author details}

'Department of Mathematical Sciences, New Jersey Institute of Technology, Newark, NJ, USA. ${ }^{2}$ Department of Mathematics, Florida State University, Tallahassee, FL, USA. ${ }^{3}$ Laboratory of Biological Modeling, NIDDK, National Institutes of Health, Bethesda, MD, USA.

Published: 18 July 2011

\section{References}

1. Gentile L, Stanley EF: A unified model of presynaptic release site gating by calcium channel domains. Eur J Neurosci 2005, 21(1):278-282.

2. Zucker RS, Fogelson AL: Relationship between transmitter release and presynaptic calcium influx when calcium enters through discrete channels. Proc Natl Acad Sci U S A 1986, 83(9):3032-3036.

3. Quastel DM, Guan YY, Saint DA: The relation between transmitter release and $\mathrm{Ca} 2+$ entry at the mouse motor nerve terminal: role of stochastic factors causing heterogeneity. Neuroscience 1992, 51(3):657-671.

4. Bertram R, Smith GD, Sherman A: Modeling study of the effects of overlapping $\mathrm{Ca} 2+$ microdomains on neurotransmitter release. Biophys $J$ 1999, 76(2):735-750.

5. Shahrezaei V, Cao A, Delaney KR: Ca2+ from one or two channels controls fusion of a single vesicle at the frog neuromuscular junction. $J$ Neurosci 2006, 26(51):13240-13249.

\section{C)


6. Matveev V, Bertram R, Sherman A: Ca2+ current versus Ca2+ channel cooperativity of exocytosis. J Neurosci 2009, 29(39):12196-12209.

7. Coggins M, Zenisek D: Evidence that exocytosis is driven by calcium entry through multiple calcium channels in goldfish retinal bipolar cells. J Neurophysiol 2009, 101(5):2601-2619.

doi:10.1186/1471-2202-12-S1-P298

Cite this article as: Matveev et al:: Effect of spatial arrangement of presynaptic calcium channels on the calcium current cooperativity of neurotransmitter release. BMC Neuroscience 2011 12(Suppl 1):P298.

Submit your next manuscript to BioMed Central and take full advantage of:

- Convenient online submission

- Thorough peer review

- No space constraints or color figure charges

- Immediate publication on acceptance

- Inclusion in PubMed, CAS, Scopus and Google Scholar

- Research which is freely available for redistribution

Submit your manuscript at www.biomedcentral.com/submit 